\title{
Completion strategy or emphasis manipulation? Task support for teaching information problem solving
}

Citation for published version (APA):

Frerejean, J., Van Strien, J., Kirschner, P. A., \& Brand-Gruwel, S. (2016). Completion strategy or emphasis manipulation? Task support for teaching information problem solving. Computers in Human Behavior, 62, 90104. https://doi.org/10.1016/j.chb.2016.03.048

DOI:

10.1016/j.chb.2016.03.048

Document status and date:

Published: 01/01/2016

Document Version:

Peer reviewed version

Document license:

CC BY-NC-ND

Please check the document version of this publication:

- A submitted manuscript is the version of the article upon submission and before peer-review. There can be important differences between the submitted version and the official published version of record. People interested in the research are advised to contact the author for the final version of the publication, or visit the DOI to the publisher's website.

- The final author version and the galley proof are versions of the publication after peer review.

- The final published version features the final layout of the paper including the volume, issue and page numbers.

Link to publication

\section{General rights}

Copyright and moral rights for the publications made accessible in the public portal are retained by the authors and/or other copyright owners and it is a condition of accessing publications that users recognise and abide by the legal requirements associated with these rights.

- Users may download and print one copy of any publication from the public portal for the purpose of private study or research.

- You may not further distribute the material or use it for any profit-making activity or commercial gain

- You may freely distribute the URL identifying the publication in the public portal.

If the publication is distributed under the terms of Article $25 f a$ of the Dutch Copyright Act, indicated by the "Taverne" license above, please follow below link for the End User Agreement:

https://www.ou.nl/taverne-agreement

Take down policy

If you believe that this document breaches copyright please contact us at:

pure-support@ou.nl

providing details and we will investigate your claim.

Downloaded from https://research.ou.nl/ on date: 26 Apr. 2023 
Completion Strategy or Emphasis Manipulation?

Task Support for Teaching Information Problem Solving

Jimmy Frerejean*, Johan L.H. van Strien, Paul A. Kirschner, Saskia Brand-Gruwel

Welten Institute, Open University of the Netherlands

Valkenburgerweg 177, 6419 AT Heerlen, Netherlands

*Corresponding author.

Email addresses: jimmy.frerejean@ou.nl, johan.vanstrien@ou.nl, paul.kirschner@ou.nl, saskia.brand-gruwel@ou.nl. 


\begin{abstract}
While most students seem to solve information problems effortlessly, research shows that the cognitive skills for effective information problem solving are often underdeveloped. Students manage to find information and formulate solutions, but the quality of their process and product is questionable. It is therefore important to develop instruction for fostering these skills. In this research, a 2-hour online intervention was presented to first-year university students with the goal to improve their information problem solving skills while investigating effects of different types of built-in task support. A training design containing completion tasks was compared to a design using emphasis manipulation. A third variant of the training combined both approaches. In two experiments, these conditions were compared to a control condition receiving conventional tasks without built-in task support. Results of both experiments show that students' information problem solving skills are underdeveloped, which underlines the necessity for formal training. While the intervention improved students' skills, no differences were found between the conditions. The authors hypothesize that the effective presentation of supportive information in the form of a modeling example at the start of the training caused a strong learning effect, which masked effects of task support. Limitations and directions for future research are presented.
\end{abstract}

Keywords: information literacy, information problem solving, completion strategy, emphasis manipulation, prompting, instructional design 


\section{Introduction}

Searching the web for information seems effortless for students; they simply navigate to a popular search engine, type in a couple keywords, and select some of the sources that appear to be relevant (MaKinster, Beghetto, \& Plucker, 2002). Most students easily find their way without any explicit instruction. They paraphrase, cite, or - in the worst case - copy and paste some of the text into their own document and the job is done (De Vries, van der Meij, \& Lazonder, 2008). The abundance of information on the internet is a bliss. While this may be viewed as a successful process in the eyes of the student, from an educational perspective it can be a waste of time. If the student is not equipped with the necessary skills, such as advanced search strategies and the ability to critically scrutinize information sources to determine relevance and reliability, chances are that the search process and the product produced fall short of what the teacher intended. It may be true that younger generations of students appear to quickly master the skills needed to navigate online information sources, but it is premature to claim that they automatically develop the skills to find correct and reliable online sources and learn from them (Kennedy, Judd, Churchward, Gray, \& Krause, 2008; Kirschner \& van Merriënboer, 2013).

Educational institutions often struggle to implement information problem solving (IPS) skills in their curricula (Badke, 2010), not just because of a lack of awareness of the importance but also because they are difficult to implement properly. Most schools offer students little more than a short library training. To prepare students for the myriad of contexts in which they will need to solve information problems during their future education and career, these skills need to be taught and practiced in different classes and across different domains throughout the whole curriculum. To support teachers and faculty in embedding IPS skills in educational curricula, it is desirable to develop evidence-based approaches to foster these skills. This paper takes a first step in that direction describing the development and 
empirical testing of instructional approaches for teaching IPS skills in an online learning environment.

\subsection{Information problem solving}

An information problem occurs when the necessary information to solve a problem is lacking. As a consequence, the problem solver needs to gather the missing information from external sources and combine the findings to construct a solution. Simple information problems, such as looking up the average monthly temperature in a country, pose little challenge for most students. Complex information problems, such as writing an essay on the effects of global warming on biodiversity, are a far more difficult challenge, because students will need to find, evaluate, and process sources of information that can vary greatly in terms of their trustworthiness, bias, reliability, or can contain contradictory information.

In educational settings, teachers often use information problems as an educational approach, expecting that having students search for information will automatically lead to their learning (Kirschner, Sweller, \& Clark, 2006). But correctly and efficiently solving an information problem is a complex higher-order cognitive competence requiring a broad range of different cognitive skills that these students might not possess. The range of skills has been summarized as a 5-stage model (see Figure 1) in which students iterate between the stages 'define the problem', 'search information', 'select information', 'process information', and 'present information', each stage consisting of several constituent skills (Brand-Gruwel, Wopereis, \& Vermetten, 2005; Brand-Gruwel, Wopereis, \& Walraven, 2009). 
Understand the task Activate prior knowledge Determine needed information Formulate question(s)

\section{Search information}

Select search strategy Generate search terms Execute search

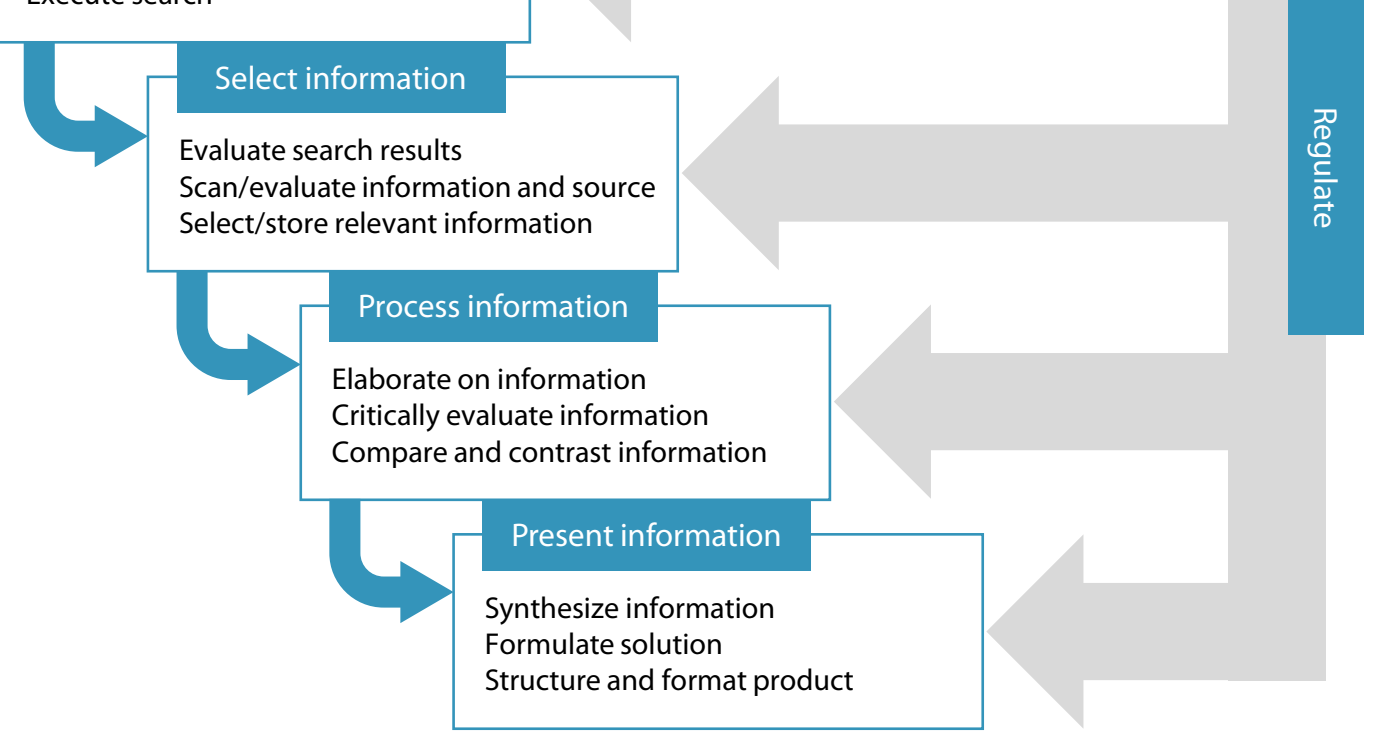

Figure 1. Decomposition of the skill 'information problem solving' (based on Brand-Gruwel et al., 2005)

To solve an information problem, the learner first needs to reach an understanding of the task and identify the needed information to define and delimit the task domain. In this stage, formulating a clear and concise question is essential to stay focused and avoid unnecessary deviations while searching. Second, search terms need to be generated and tried out in a search engine. By identifying key concepts from the question and then systematically changing, adding, or removing terms while correctly using the available Boolean operators, the learner maximizes the chance to find relevant information sources. Third, it is important to maintain a critical attitude while evaluating the search results page, the subsequently visited information sources, and the information itself. Critical scrutiny avoids spending time 
on irrelevant websites or becoming occupied with information that is outdated, false, or which originates from unreliable or biased sources. Fourth, when relevant and reliable sources are found and stored, the learner needs to process their contents, deal with overlapping and conflicting information, and synthesize the different elements chosen from the separate sources. Finally, the solution can be presented in a product such as an essay or a presentation, depending on the task. It is important that the product clearly answers the question that was defined earlier in the task. Moreover, during all of these steps, the learner should regulate the search process, decide whether sufficient useful information has been found, and steer the process to avoid deviations or distractions.

Previous research shows that while students may quickly develop the instrumental skills needed to operate digital devices and use software and internet browsers, IPS skills are generally either underdeveloped or absent (for a review, see Walraven, Brand-Gruwel, \& Boshuizen, 2008). Several research studies have described the problems that occur when novices search the web for information. For example, novice searchers tend to spend little time reading the task, defining the problem, and activating prior knowledge when compared to experts (Brand-Gruwel et al., 2005). Generating keywords causes problems as well, as novices tend to choose incorrect keywords and misuse Boolean operators, making many small and ineffective changes to their search query in the process (Hölscher \& Strube, 2000; MaKinster et al., 2002). Novices often do not know how to correctly evaluate information sources (i.e., the sites found) and the information presented in them, sometimes leading to incorrect or irrelevant information for solving the problem (Britt \& Aglinskas, 2002; Gerjets, Kammerer, \& Werner, 2011). In comparison, expert searchers tend to judge information and sources more often, elaborate more on the information found, and regulate their search process more often (Brand-Gruwel et al., 2005; Stadtler \& Bromme, 2008). 
From these findings it becomes clear that IPS is a complex high-order cognitive skill that is often lacking in students and other novices searching the web. In general, IPS skills may not be of the level that is often expected of the student problem solver, or from the socalled 'digital natives' (see also: Kirschner \& van Merriënboer, 2013), which warrants developing and deploying explicit forms of instruction for IPS in schools.

\subsection{Instructional principles of IPS training}

There are several reasons why teaching IPS is more than simply providing students with a systematic approach to solving them. Contrary to well-defined problems, which often have discrete solution steps that are guaranteed to lead to a solution (e.g., in mathematics), information problems are often ill-defined, requiring heuristics and strategies that often depend on the nature of the task and the problem context. For example, a student who solves an information problem about global warming and biodiversity ideally acquires the domainspecific knowledge (e.g., geographic, meteorological, biological concepts) and applies a certain set of necessary problem solving skills. When that student next encounters a completely different problem domain (e.g., history) in a subsequent task, a different set of heuristics and strategies might be more effective. Research has shown that in web search, students who lack either domain-specific knowledge or web searching skills perform poorly and students who lack both are especially worse off (Hölscher \& Strube, 2000). This demonstrates that information problems are in essence always dual-layered, and instruction needs also to take possible differences in problem context into account.

While this dual-layered nature of information problems makes designing instruction challenging, task domain is not the only factor that influences the problem solving process, and in consequence, learning and instruction. Rouet (2009) summarizes additional factors in a conceptual framework comprising three dimensions: individual variables, information 
resources, and problem context. Instructional designers should be aware that personal factors, such as an individual's domain-specific knowledge (Bråten, Strømsø, \& Salmerón, 2011), attitudes and biases (Ford, Miller, \& Moss, 2005; Van Strien, Brand-Gruwel, \& Boshuizen, 2014), epistemic beliefs (Kammerer, Bråten, Gerjets, \& Strømsø, 2012), and reading skills (Rouet, Ros, Goumi, Macedo-Rouet, \& Dinet, 2011) can affect the learning processes and outcomes. Similarly, source factors (DeStefano \& LeFevre, 2007) and task type (Wirth, Sommer, von Pape, \& Karnowski, 2015) may influence variables in the learning process. While most of these factors lie outside the designer's influence, they all affect the demand imposed on working memory during the IPS process. When this demand becomes too high, it can negatively impact learning (Paas \& van Merriënboer, 1994).

With so many elements that potentially increase the amount of cognitive load experienced by the student, it is essential that instructional designers take great care to reduce unnecessary load, yet maintain activities that induce germane load and lead to learning. The Four Component Instructional Design (4C/ID) model provides an extensive blueprint and approach for developing instruction to teach complex cognitive skills, based on solid psychological and educational research (Van Merriënboer \& Kirschner, 2013). First, the model recommends designing instruction that uses authentic, whole tasks so students learn the interrelations among the performed skills. Second, it provides guidelines to correctly provide the information needed to solve the problems, such as a structured approach to problem solving. Third, it advises providing procedural information to aid problem-solvers with routine tasks, when it is needed (just-in-time) during the tasks. The fourth component, part-task practice, is particularly beneficial for recurring motor skills and seems less useful in the current context, although in theory it could be used to target recurring cognitive skills, such as working with Boolean operators. Particularly the first three components provide guidelines that are suited for developing an IPS intervention. 
The 4C/ID model stresses the importance of built-in task support in cases where tasks are too complex for a learner to complete successfully. While learners can be supported in many ways (i.e. with case studies, modeling and/or worked examples, inducing reflection, etc.), the current experiments focus on two approaches that appear most applicable to IPS instruction, namely the completion strategy and emphasis manipulation.

\subsection{Completion tasks}

A completion task is a problem where the learner is provided with a given state and a partial solution. After studying the partial solution and the given information, the learner then has to complete the remaining solution steps in order to solve the problem (Van Merriënboer, 1990; Van Merriënboer \& De Croock, 1995). This approach is effective for several reasons. First, they inherently stimulate active processing of the given solution steps because they contain essential information the learner needs to process before being able to continue. In addition, the provided solution steps are examples of a correct systematic approach to solving the problem. This enables learners to study the examples and by induction generate schemas of correct solution strategies themselves. Studying correct examples (albeit partial solutions) can often be more effective than solving whole problems, especially early in the learning process (Renkl \& Atkinson, 2003). When learners lack the necessary schemas and strategies, they will fall back to naïve and ineffective strategies such as means-end analyses or trial-and-error to solve the problem. Providing sufficient worked-out steps in this phase can avoid this (Van Gog, Paas, \& van Merriënboer, 2004).

The second benefit of using completion tasks is that a designer can change the number of worked-out steps to adapt the task to the learner's level. For learners in an early learning phase, it would be beneficial to increase the number of worked-out steps (e.g., one or even no steps missing), providing ample examples of correct complete or partial solutions 
and allowing the learner to induce the necessary schemas and strategies (Atkinson, Renkl, \& Merrill, 2003; Renkl, Atkinson, \& Große, 2004). In later learning phase, learners benefit more from more conventional tasks that contain just a few worked-out steps. Offering too many worked-out steps to these learners would create the risk of inducing the expertisereversal effect (Kalyuga, Ayres, Chandler, \& Sweller, 2003; Kalyuga \& Sweller, 2004). By gradually reducing the number of worked-out steps as a learner progresses, the amount of support that is offered corresponds more closely to the amount of support that is actually needed. In the context of IPS, this fading of solution steps can only be applied backward, meaning that worked-out solution steps late in the process will always fade before solution steps early in the process. To illustrate, consider the opposite: A worked-out example where the solution and information sources are given but the student needs to define the problem and generate search terms. Such a backward information problem is unrealistic, and practicing it has little purpose. In conclusion, a gradual transition from completely workedout problems to conventional problems would be a good strategy for instruction: an approach dubbed the completion strategy.

In the context of an information problem, a completion task could provide students with a problem orientation, a well-formulated problem statement and research question, and a partial list of search terms. In this case, the step 'problem definition' is completely worked out, and the step 'searching' is partially worked out. Students will need to process the problem orientation to become familiar with the task domain and to activate any prior knowledge. The given problem statement and research question provide a clear direction for the search and inform them which information is needed, and consequently, which information is not. Based on this orientation, students can then extend the list of search terms and proceed with the remaining solution steps ('select information', 'process information', and 'present information') in order to finally solve the problem. Compared to a conventional 
task where students perform the whole task, this approach requires less decision making - and therefore less room for error - and provides an additional example to learn from. The expectation here is that such tasks will impose fewer cognitive demands than conventional problems.

\subsection{Emphasis manipulation}

Students can also be supported by guiding them in the allocation of their attention to a certain skill (i.e., generating search terms) or a step in the process (i.e., selecting information) within a learning task. Students then perform the whole task from beginning to end, but just one aspect of the solution procedure is emphasized, often by instructions and feedback. In subsequent tasks, the emphasis and thus the allocation of the learner's attention shifts to a different aspect of the task. Note that the task is not broken up into part-tasks, but only the relative emphasis of the selected aspect varies. All skills are still performed in the context of the whole task. This approach, called emphasis manipulation or emphasis change (Gopher, 2006; Gopher, Weil, \& Siegel, 1989), reduces strain on working memory because not all instruction needs to be kept available in working memory, and attention is focused on a single aspect, not divided over all aspects.

The emphasis change approach was effective in a training regime for a highworkload computer game called Space Fortress and in several dual-task settings (Gopher, 2006). In other research, students who received whole-task training with emphasis change were less easily disrupted by a concurrent task than students receiving part-task training (Fabiani et al., 1989). In addition, Yechiam, Erev, and Gopher (2001) demonstrated that an emphasis change approach is more effective than guided instruction in settings where searchers quickly converge to suboptimal strategies. The idea here is that problem solvers make only small changes to their current, suboptimal, strategy and insufficiently explore 
more diverse solution strategies, a process called melioration (Yechiam, Erev, Yehene, \& Gopher, 2003). Emphasis change protocols facilitate the exploration of other, potentially more effective strategies.

The errors that can be observed when novices search the web may be a sign of melioration. Lacking sufficient skill, they employ naive strategies that will find some results (partly due to increasing quality of search engines), even though it may not be the information they are looking for. This will then lead them to obtaining suboptimal information, which in turn leads to a suboptimal solution to the task. Students experience the success of solving the problem, which reinforces their current behavior and leads to a similar approach to the next problem. Students see no reason to expend extra effort to significantly change their strategy. Emphasis change can encourage students to explore other strategies, such as more extensive planning, or using thesauri to generate keywords, which increases the chance of a more effective or efficient problem solving process.

Placing emphasis on specific aspects of a task can be done by incorporating instruction and feedback during those specific aspects of the learning task. A simple and effective method to provide instruction and feedback in an online environment is by using prompts (see: Stadtler \& Bromme, 2008). In the case of IPS, three types of prompts are effective: anticipative prompts delivered before execution of the targeted skill, instructional prompts delivered just in time before execution of the targeted skill, and reflection prompts delivered after performing the skill.

Consider a student working on a learning task where the skill evaluating sources is emphasized and therefore accompanied by prompts. Before she starts evaluating sources (i.e., the targeted skill), she is prompted: "Describe your approach to the next step. Where will you focus your attention?” By articulating her upcoming actions before performing the skill, anticipative reasoning, a skill found in effective problem solvers, is stimulated (Renkl, 1997). 
The student answers: "I'll look at the result list and click on some of the titles that seem interesting. I'll then read that text. If it seems relevant, I'll probably use it." The answer reveals that her solution schema is still incomplete, and that she has not yet learned to evaluate a search engine results page or an information source. Merely activating knowledge is therefore not sufficient. Her current schemas or strategies need to be corrected or completed.

She is prompted again, this time simply with instructions. The instructional prompt explains how to evaluate search results (i.e., pay attention to domain names, publication dates, snippets) before clicking a link and how to judge information sources (i.e., take into account author reputation, target audience, information goal, publication date). It essentially gives general feedback on her previous answer. The student will acknowledge that her previously articulated approach was incomplete and that she should not merely click 'interesting' links and use 'relevant' information. She learns that there are many more criteria to use to discriminate between interesting and relevant. She then processes this information and immediately carries out the solution step, with this new knowledge in memory. The subsequent application of the new knowledge stimulates assimilation into knowledge schemas.

To enforce this process, a reflection prompt can be delivered after the step is performed: "How did it go? Did you encounter any problems?" This prompt induces reflection and forces her to look back at how she applied the new knowledge, which should reinforce the use of a correct or more effective solution strategy (Saito \& Miwa, 2007; Stark \& Krause, 2009). Taken together, this combination of three prompts, the prompt triad, fulfills the purpose of emphasis manipulation by first lowering cognitive demand by focusing student attention to a particular aspect of the task while leaving the whole task intact and then 
promoting improvements in strategies by activating and correcting current knowledge schema.

\subsection{The present study}

In the current study, two experiments were conducted to investigate the effects of these two forms of task support (completion strategy vs. emphasis manipulation) on the acquisition of IPS skills in a short online training. This training was embedded as a standalone practical assignment in university students' first-year curriculum. As an intervention in a naturalistic classroom setting, this training aimed to develop students' IPS skills while detecting differences in the extent of learned skills due to the different methods of support. It was expected that students who receive at least one form of task support (i.e., completion tasks and/or emphasis manipulation) will perform better than students who do not receive task support (Hypothesis 1) and students who receive a combination of both forms of support will perform better than students who receive only a single form of support (Hypothesis 2). To help explain differences in learning outcomes, students were asked to report the required mental effort at several points during the learning phase. 


\section{Experiment 1}

\subsection{Method}

\subsubsection{Participants}

A total of 96 students between 18 and 24 years old $\left(M_{\text {age }}=18.7\right.$ years $)$ participated in this experiment, 89 of whom were female $(92.7 \%)$ and 7 were male (7.3\%). All participants were first-year Pedagogical Science students at a Belgian university.

\subsubsection{Experimental design}

The experiment was a regular pretest-posttest design with four conditions. All conditions received a training with four learning tasks, but three learning tasks varied in the type of support given. The first condition received a version of the training combining both approaches, namely the completion strategy combined with emphasis manipulation (CS+EM). A second condition received completion tasks, but no emphasis prompts (CS). The third condition received emphasis prompts, but no completion tasks (EM). The fourth condition was a control condition and received conventional learning tasks without support. Table 1 presents an overview of how task support was incorporated for each condition.

Due to time constraints, it was not possible to add task support to each of the five solution steps and simultaneously give students a variety of tasks to work on. The experimenters therefore made a deliberate choice to merge the steps 'selecting' and 'processing' in the learning tasks, as this is often done concurrently. No task support was supplied on the final step: 'presenting' as presenting information can be done in countless ways. Providing support on this skill would be very time-consuming and students would 
likely benefit more from support on the first four steps than from support on presenting information.

The CS+EM and CS conditions received completion tasks. In these tasks, some solution steps are already worked out. Students receiving a worked-out step viewed a very short video (approximately 1 to 2 minutes) of a fictitious expert reasoning through the solution step. No further action was required. The worked-out steps were faded, meaning each subsequent learning task contained one less worked-out step and students were therefore required to perform one step more in each learning task. The fading occurred backwards, meaning later steps in the process, such as 'presenting information' and 'processing information', were removed first and the first step - 'define the problem' - was removed last.

In the CS+EM and EM conditions, each learning task contained one solution step that was emphasized with a prompt triad: an anticipative prompt and an instructional prompt before execution of the step, and a reflective prompt afterwards. Again, this extra support mechanism was only added to the first four steps. In the CS+EM condition, these prompts were added to the first step that followed the worked-out steps. In the EM condition, the same step was selected to receive emphasis. The control condition received conventional learning tasks that guided students through the solution steps but contained no additional support. 
Table 1

Overview of support mechanisms added to the learning tasks per condition

\begin{tabular}{llllll}
\hline $\begin{array}{l}\text { Learning tasks } \\
\text { (topic) }\end{array}$ & $\begin{array}{l}\text { Problem } \\
\text { Solving steps }\end{array}$ & CS+EM & CS & EM & Control \\
\hline Task 1 & Define & Worked-out & Worked- & - & - \\
(stretching & Search & Worked-out & out & - & - \\
before sports) & Select \& & Emphasized & Worked- & Emphasized & - \\
& Process & - & out & - & - \\
& Present & & - & & \\
& & & - & - & - \\
\hline Task 2 & Define & Worked-out & Worked- & - & - \\
(electromagnetic & Search & Emphasized & out & Emphasized & - \\
radiation from & Select \& & - & - & - & - \\
cellphones) & Process & - & - & - & - \\
& Present & & - & & - \\
\hline Task 3 & Define & Emphasized & - & Emphasized & - \\
(violence and & Search & - & - & - & - \\
videogames) & Select \& & - & - & - & - \\
& Process & - & - & - & - \\
& Present & & - & - & - \\
\hline Task 4 & Define & - & - & - \\
(use of media & Search & - & - & - & - \\
devices before & Select \& & - & - & - & - \\
sleeping) & Process & - & - & - & - \\
\hline
\end{tabular}

Note: The steps 'Select' and 'Process' were merged and presented as a single step.

There was no support on the step 'Present'. A dash (-) indicates no support on that step.

\subsubsection{Procedure}

The training was embedded in the students' current curriculum as a practical assignment and offered in four different timeslots. Students were free to choose a timeslot that fit their schedule. During the 2-hour training session, students took place at a computer in the university computer room and logged in to the online learning environment. After logging in, students first filled out a short demographic questionnaire and were automatically randomly assigned to one of four conditions. They were instructed to work individually through the tasks they received on screen and informed that their screen content could differ from that of the other students. The experimenter asked students to spend approximately 15 minutes on 
each learning task, comparable to similar tasks used in other research (Lazonder, Biemans, \& Wopereis, 2000; Lazonder, 2000). They then received the following: pretest, instructional video, modeling example, four learning tasks, and posttest. Each learning task concluded with the mental effort and time-pressure ratings. The instructional video and modeling example remained available via a link during the learning tasks. Before the posttest, students filled out a short evaluation and a final mental effort rating for the training as a whole. After the posttest, students signed for informed consent, received course credit and were subsequently dismissed. A debriefing with preliminary results followed 8 weeks later.

\subsection{Materials}

\subsubsection{Pretest and posttest}

The online experimental environment included two skills tests: a pretest and a posttest, both consisting of seven items presenting fabricated situations that occur during an information problem. For example, one item showed a fabricated SERP (search engine results page) and asked students to indicate which sources they would select and why. Each item measured a different subskill in the process. The items in the posttest were identical to the pretest, but on a different subject (i.e., problem domain). Answers were scored based on a task-specific rubric that resulted in a maximum subscore of 4 points per step, for a maximum total of 16 points. The step 'presenting' was not measured because presentation of a problem solution is a multifaceted skill too difficult to measure quickly, and the training did not include support on this step. A second experimenter rescored 20 randomly chosen participants in order to obtain a measure of inter-rater agreement. Table 2 provides an overview of the pretest and posttest items. 
Table 2

Overview of pretest and posttest

\begin{tabular}{|c|c|c|c|c|}
\hline Item & Step & Subskill & Given & Question \\
\hline 1 & $\begin{array}{l}\text { Problem } \\
\text { definition }\end{array}$ & $\begin{array}{l}\text { Problem } \\
\text { orientation }\end{array}$ & $\begin{array}{l}\text { A problem } \\
\text { description }\end{array}$ & $\begin{array}{l}\text { How would you start this task? } \\
\text { What is your first step and } \\
\text { why? }\end{array}$ \\
\hline 2 & $\begin{array}{l}\text { Problem } \\
\text { definition }\end{array}$ & $\begin{array}{l}\text { Formulating a } \\
\text { problem } \\
\text { statement }\end{array}$ & $\begin{array}{l}\text { A problem } \\
\text { description }\end{array}$ & $\begin{array}{l}\text { Which problem statements } \\
\text { would you formulate? Why do } \\
\text { you choose these? }\end{array}$ \\
\hline 3 & $\begin{array}{l}\text { Search } \\
\text { information }\end{array}$ & $\begin{array}{l}\text { Generating } \\
\text { search terms }\end{array}$ & $\begin{array}{l}\text { A problem } \\
\text { description }\end{array}$ & $\begin{array}{l}\text { Which search query would you } \\
\text { type into Google? Formulate } \\
\text { two alternative search queries. }\end{array}$ \\
\hline 4 & $\begin{array}{l}\text { Selecting } \\
\text { information }\end{array}$ & $\begin{array}{l}\text { Evaluating } \\
\text { search results }\end{array}$ & $\begin{array}{l}\text { A fabricated } \\
\text { SERP }\end{array}$ & $\begin{array}{l}\text { Which three websites would } \\
\text { you select? Why did you select } \\
\text { these websites? }\end{array}$ \\
\hline 5 & $\begin{array}{l}\text { Processing } \\
\text { information }\end{array}$ & $\begin{array}{l}\text { Scanning a } \\
\text { source }\end{array}$ & $\begin{array}{l}\text { A screenshot of } \\
\text { a text-rich } \\
\text { website, } \\
\text { zoomed so the } \\
\text { text is } \\
\text { unreadable }\end{array}$ & $\begin{array}{l}\text { What do you do when you visit } \\
\text { a text-rich website and want to } \\
\text { find out if it contains relevant } \\
\text { information? How do you } \\
\text { proceed? }\end{array}$ \\
\hline 6 & $\begin{array}{l}\text { Processing } \\
\text { information }\end{array}$ & $\begin{array}{l}\text { Evaluating } \\
\text { information }\end{array}$ & $\begin{array}{l}\text { A short text } \\
\text { fragment } \\
\text { containing an } \\
\text { argument given } \\
\text { by an expert }\end{array}$ & $\begin{array}{l}\text { Which criteria do you use to } \\
\text { determine whether information } \\
\text { is useful for your task? What } \\
\text { are your conditions for use? }\end{array}$ \\
\hline 7 & $\begin{array}{l}\text { Processing } \\
\text { information }\end{array}$ & $\begin{array}{l}\text { Dealing with } \\
\text { conflicting } \\
\text { information }\end{array}$ & $\begin{array}{l}\text { Two short, } \\
\text { contradicting } \\
\text { arguments }\end{array}$ & $\begin{array}{l}\text { How do you deal with } \\
\text { contradicting information? How } \\
\text { does this affect your solution? } \\
\text { Explain. }\end{array}$ \\
\hline
\end{tabular}

\subsubsection{Learning phase}

The training started with a 14-minute instructional video introducing the IPS process and the five steps (i.e., 'define', 'search', 'select', 'study', 'present') including their constituent skills. The instructional video was followed by a modeling example: a 10-minute screencast in which a fictitious expert showed a systematic approach to solving an information problem. 
This modeling example was split into four short fragments that ended with the questions "What do you think of the actions of the expert?" and "How does this differ from your current approach?" intended to stimulate students to formulate explanations and stimulate active processing of the example (Atkinson et al., 2003; Renkl \& Atkinson, 2002). These elements formed the supportive information component in the 4C/ID model.

The training comprised four learning tasks in the form of a web search exercise. Students received a problem description and had approximately 15 minutes to search the web for information and formulate a solution to the problem. The learning tasks guided students through the problem solving steps with on-screen instructions - forming the procedural information component. Students were asked to explicitly formulate research questions and search terms, and list the URL of four sources that contributed to their solution, along with an explanation of why they chose these sources. At the end, they formulated a solution in a few sentences. Each of the different experimental conditions received a different form of support during three learning tasks (see Table 1). A fourth and final task was presented that did not include any support or guidance, but simply gave a problem description and a textbox for an answer. This task was identical for all students and contained no explicit instruction.

\subsubsection{Mental effort}

To measure invested mental effort during the learning phase, each learning task ended with a short measurement of experienced mental effort: a 9-point mental effort rating scale (Paas, 1992): How much effort did it take to perform this task? All students were instructed to spend approximately 15 minutes on each learning task. To assess whether the extra prompts and worked-out steps caused time pressure for students, the temporal demand item from the NASA-TLX (Hart \& Staveland, 1998) was also included: How hurried or rushed was the pace of the task? 


\subsection{Data analysis}

The scores on the pretest and posttest were analyzed with a repeated measures analysis of variance with type of support (CS+EM vs CS vs EM vs Control) as a between-subjects variable and time of test (pretest vs posttest) as a within-subjects variable. The same analysis was conducted on the subjective mental effort rating and the time pressure rating but with learning task as a within-subjects variable. In addition, an analysis of variance was conducted on the ratings per learning task to investigate differences in required mental effort between conditions.

\subsection{Results}

The four randomly generated conditions did not differ significantly on any of the demographic data such as age or prior education. They reported equal amounts of time spent behind a computer per day, and no differences in the use of the computer for information retrieval (either for personal or educational goals), news, social media, chatting, and entertainment. The sample can therefore be considered homogeneous. Some data were scored as missing due to the fact that students answered questions with a dash or a space, and some data were lost due to incidental technical problems. On the posttest, missing values were substituted for their corresponding scores on the pretest as a best-guess - and indicating no progress - under the condition that only one value in that step was missing. If more values were missing, the corresponding subscore was also classified as missing data. Total scores on the posttest were treated the same: if more than one of the four subscores was missing, they were classified as missing value, otherwise the total was calculated over the remaining subscores. 


\subsubsection{Pretest and posttest scores}

Inter-rater agreement on the scoring rubric for pre- and posttest was measured with a twoway mixed, absolute, single measure intra-class correlation and amounted to .878 , indicating a reliable measure. Students scored rather low on the pretest, achieving a mean score of $41.86 \%(S D=9.86)$. The scores varied between $18.75 \%$ and $62.5 \%$. On the posttest, the mean score improved to $60.55 \%(S D=11.16)$ with a range from $31.25 \%$ to $81.25 \%$. Table 3 shows the mean scores per condition for the pretest and posttest. The repeated measures analysis showed that the between-subjects factor was not statistically significant: $F(3,92)=.971, p=.410$, meaning that there was no effect of support and the scores did not depend on the type of support received. Indeed, the mean scores in Table 3 reveal that the four groups show a similar progression. The within-subjects factor did reveal a significant effect: $F(1,92)=187,462, p=.000, \eta^{2}$ partial $=.671$, indicating there was a substantial effect of training on the test scores.

Table 3

Overview of scores (in percentage) per condition

\begin{tabular}{lcc}
\hline Condition & Pretest $(S D)$ & Posttest $(S D)$ \\
\hline EM & $43.75(11.89)$ & $63.07(10.19)$ \\
CS & $41.25(9.02)$ & $62.25(11.05)$ \\
CS+EM & $41.75(8.79)$ & $58.50(12.48)$ \\
Control & $40.89(10.09)$ & $58.59(10.56)$ \\
\hline Total & $41.86(9.86)$ & $60.55(11.16)$ \\
\hline
\end{tabular}

\subsubsection{Mental effort ratings}

The mental effort ratings showed a similar pattern: significant changes over learning tasks, but not between the conditions: The repeated measures analyses revealed no significant between-subjects effect $F(3,90)=.638, p=.593$, but a significant within-subjects effect 
$F(3,90)=9.602, p=.000, \eta_{\text {partial }}^{2}=.100$. Contrast analysis further revealed that reported mental effort drops significantly from $5.21(S D=2.03)$ in learning task 3 to $4.36(S D=1.89)$ in learning task $4: F(1,90)=18.136, p=.000, \eta_{\text {partial }}^{2}=.174$. Univariate ANOVAs per learning task revealed no differences between conditions.

\subsubsection{Time pressure}

Analysis of time pressure showed that although scores were relatively high (all means above 5 on the 7-point scale), there were no within-subjects differences: $F(3,89)=1.005, p=.391$ or between-subjects differences: $F(3,89)=.160, p=.923$. Therefore, students experienced similar time pressure in all conditions and in all learning tasks. Univariate ANOVAs per learning task confirmed this finding: on all four learning tasks, differences between conditions were not statistically significant. Figure 1 shows mean mental effort and time pressure ratings for each condition and each learning task. 

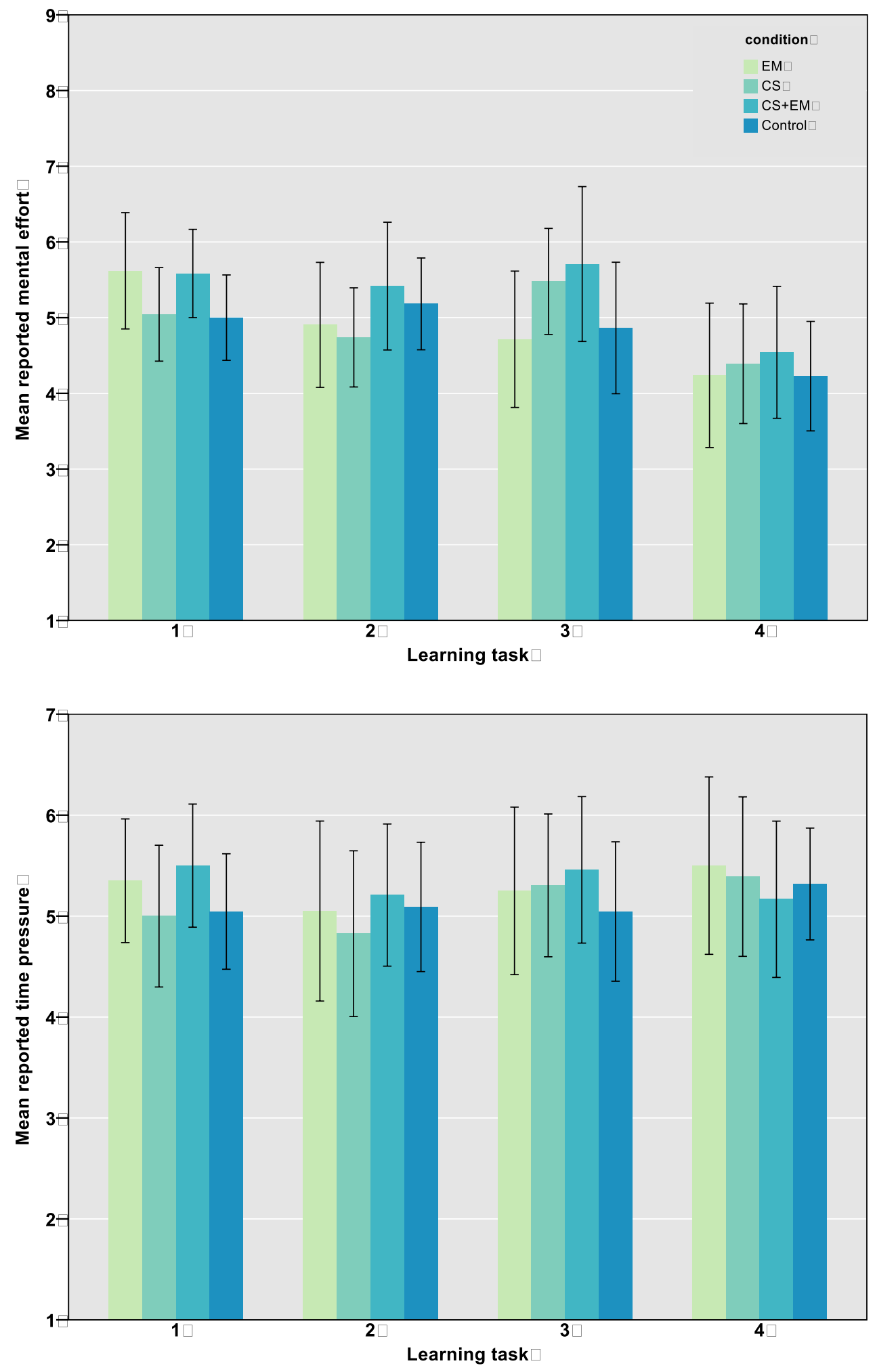

Figure 1. Overview of reported mental effort per learning task for all conditions 


\subsection{Discussion}

This experiment was designed to explore whether the acquisition of IPS skills was affected by different forms of task support. However, the results show that all groups show similar increases in skill. These findings do not provide support for the hypotheses that 1) supported students show higher learning outcomes than unsupported students, and 2) two forms of support lead to higher learning outcomes than just one form of support. As a matter of fact, the control group, which merely received conventional tasks without any built-in support, performed just as well as the three groups who received task support. There was a significant increase in scores from pretest to posttest for all conditions, showing that the intervention clearly caused a learning effect. From this finding, it can be concluded that even a short online training, much like the training sessions often offered by schools, can be effective for fostering IPS skills. While the results clearly show a short-term learning effect, it is unclear whether there is potential to achieve a long-term effect. Additionally, the different types of support might have different effects on retention, which only manifest when measured after sufficient delay, or are induced by testing (i.e., a testing effect: Dirkx, Kester, \& Kirschner, 2014). No such delayed measurement was undertaken in this experiment. It would therefore be interesting to investigate delayed learning effect with a retention test.

In line with these findings, students reported a similar amount of required mental effort in all conditions. For this category of students and in this particular setting, online learning tasks with or without built-in task support, whether that is completed steps or emphasized aspects, are equally demanding in terms of mental effort. From this self-report of mental effort, it is only possible to gauge the total amount of experienced cognitive demand, but not changes in the underlying types of cognitive load. If worked-out steps reduced intrinsic cognitive load but required students to invest additional mental effort to process and self-explain the worked-out steps, it replaced intrinsic with germane cognitive load and there 
might be no change in the total amount of experienced cognitive load (Paas, Tuovinen, Tabbers, \& Van Gerven, 2003). Similarly, if prompting leads to more extraneous cognitive load and less invested energy in learning, germane load is reduced but the total amount of cognitive load remains the same. However, when intrinsic or extraneous load is replaced with germane cognitive load, this hypothetically leads to increased learning (Van Merriënboer \& Ayres, 2005). It is unlikely that this has happened, because increased learning would manifest as higher scores on the skills tests, which were not found. From the current data, the only valid conclusion is that the different types of support have no effect on the total amount of experienced cognitive load.

The high scores on the time pressure item revealed that many students experienced time pressure to finish the experiment. In the short evaluation at the end of the training 43 out of 96 participants made a remark about experienced time pressure. From their comments it became clear that the lack of time affected their concentration and performance during the learning tasks, or answer quality on the posttest. These students reported they took less time to think about and formulate their answers, thereby perhaps leaving out parts of the reasoning and missing points. This makes it likely that the learning outcomes are affected and possibly lowered because of time pressure. Given more time per task, students would perhaps have scored differently.

Inspection of students' solutions on the learning tasks revealed a great variation in answers. However, there was little instruction on presenting a solution incorporated in the training, so it cannot be expected that these outcomes correspond strongly to the level of their searching skills. Performance on the learning tasks was not part of the experimental design, and therefore, students' products were not scored and analyzed. For this reason it is not possible to comment on the students' performance during the learning phase. 


\section{Experiment 2}

A second experiment was conducted with the same goal as the first experiment: to investigate differences in learning outcomes due to different types of task support. The same design and conditions were used as in the first experiment, but materials and procedures were slightly improved.

\subsection{Method}

\subsubsection{Participants}

A total of 115 students between 18 and 46 years old participated in the replication $\left(M_{\text {age }}=20.7\right.$ years), 82 of which were female $(71.3 \%)$ and 33 male $(28.7 \%)$. These were all first-year Psychology students at a Dutch university. Of these 115 students, three had a Belgian nationality (2.6\%) and 48 were German (41.7\%). The remainder was Dutch. Participation was voluntary, but strongly stimulated by granting research participation credit and informing students that the content of the training corresponded strongly to one of the course tasks about problem solving. The session was offered in eight different timeslots. Again, students were free to choose a timeslot that fit their schedule. The length of the training session remained 2 hours. The expectation was that an extension of the session length risked demotivating and tiring students. However, students were informed that an online pretest and delayed posttest had to be filled out in their own time, which allowed more time for the learning tasks. A debriefing followed in a lecture 2 weeks after the retention test.

\subsubsection{Experimental design and procedure}

The procedure and design were largely identical to the procedure of the first experiment, with the exception that the pretest was filled out at home, 1 week before the training and the 
retention test was filled out at home, 1 week after the training. For the training session, the experimenter stimulated students to spend approximately 20 minutes on each learning task which was 5 minutes (33\%) longer per task than in Experiment 1, to avoid time pressure at the end of the session. After finishing the final evaluation, students signed a form to obtain research participation credit and were reminded to fill out the retention test after 1 week. They were then dismissed.

\subsection{Materials}

\subsubsection{Pretest, posttest, and retention test}

The same pretest and posttest were used as in Experiment 1, but a retention test was added. This retention test was identical to the existing pre- and posttests, but handled a different topic. Furthermore, a self-report questionnaire was added to the pretest, posttest and retention test.

\subsubsection{Self-report questionnaire}

The self-report questionnaire was based on an existing questionnaire (Van Meeuwen, 2008) and contained 30 items to measure students' systematic approach and evaluation behavior; for example: "I check whether a page is up-to-date before I use its information". Students responded to these items by selecting 'Never', 'Sometimes', 'Often', or 'Always'. The questionnaire included an 'I don't know' option to reduce guessing.

\subsection{Data analysis}

The pretest, posttest, and retention test were scored as in Experiment 1 and subjected to a repeated measures analysis of variance with type of support (CS+EM vs CS vs EM vs control) as a between-subjects variable and time of test (pretest vs posttest vs retention test) as 
a within-subjects variable. Mental effort and time pressure ratings were analyzed with a repeated measures analysis of variance with learning task as a within-subjects variable. In addition, a univariate analysis of variance was conducted on the mental effort and time pressure items per learning task to investigate differences in required mental effort between conditions.

For the self-report scale, a principle component analysis with oblimin rotation was conducted on the 30 -item scale in a larger sample size $(n=250)$ to extract underlying clusters and form scales. A mean value was calculated for each cluster by averaging the scores on the corresponding items. The 'I don't know' answer was treated as a missing value, and averages were only calculated if there was no more than one missing value. Scores were analyzed with a repeated measures analysis of variance.

\subsection{Results}

As in Experiment 1, analysis of demographic data revealed a homogeneous group in terms of age and prior education. No notable differences arose in computer usage patterns or time spent behind the computer per day. Again, some data was missing, which was handled in the same way as in Experiment 1.

\subsubsection{Pretest, posttest, and retention test}

The scores on the pretest ranged between $12.5 \%$ and $62.5 \%$ with a mean of $35.14 \%$ $(S D=11.18)$. For the posttest, scores ranged between $37.5 \%$ and $83.33 \%$ with a mean score of $61.58 \%(S D=11.15)$. On the retention test the mean score was $60.6 \%(S D=13.73)$ with a minimum score of $25 \%$ and a maximum score of $87.5 \%$. Table 3 shows the mean scores per condition for the three tests. The results resemble those of the first experiment and show an increase in scores after training, but little difference between the conditions. The repeated 
measures analysis confirms that there was no significant difference between the groups:

$F(3,102)=1.087, p=.358$ but a significant difference on the within-subjects factor:

$F(2,102)=236,401, p<.001, \eta_{\text {partial }}^{2}=.699$. This confirms that there was a substantial effect

of training on the test scores. A planned contrast revealed that the increase in scores from

pretest to posttest was statistically significant: $F(1,102)=383,032, p<.001, \eta_{\text {partial }}^{2}=.790$,

but the scores did not change significantly on the retention test: $F(1,102)=0,716, p=.400$.

There were no significant interaction effects.

Table 3

Means and standard deviations of scores on the skills test (in percentages), systematic

approach ratings (0-3), and evaluation behavior ratings (0-3) per condition on the pretest, posttest, and retention test.

\begin{tabular}{llccc}
\hline Condition & & Pretest & Posttest & Retention test \\
\hline EM & Score & $34.72(11.93)$ & $58.33(11.88)$ & $58.80(12.41)$ \\
& Systematic & $1.22(.36)$ & $1.28(.38)$ & $1.39(.43)$ \\
& Evaluation & $1.57(.42)$ & $1.76(.33)$ & $1.89(.44)$ \\
\hline CS & Score & $34.25(8.86)$ & $63.58(9.14)$ & $60.50(14.96)$ \\
& Systematic & $1.08(.41)$ & $1.22(.43)$ & $1.32(.45)$ \\
& Evaluation & $1.53(.47)$ & $1.78(.57)$ & $1.94(.42)$ \\
\hline CS+EM & Score & $36.22(12.63)$ & $63.06(12.20)$ & $64.90(13.93)$ \\
& Systematic & $1.20(.44)$ & $1.41(.41)$ & $1.32(.40)$ \\
& Evaluation & $1.74(.50)$ & $1.87(.47)$ & $1.93(.46)$ \\
\hline Control & Score & $35.27(12.41)$ & $61.09(10.79)$ & $57.14(14.00)$ \\
& Systematic & $1.24(.43)$ & $1.34(.39)$ & $1.33(.49)$ \\
& Evaluation & $1.52(.47)$ & $1.95(.35)$ & $1.92(.42)$ \\
\hline \multirow{2}{*}{ Total } & Score & $35.14(11.18)$ & $61.58(11.15)$ & $60.60(13.73)$ \\
& Systematic & $1.19(.39)$ & $1.32(.39)$ & $1.34(.42)$ \\
& Evaluation & $1.57(.48)$ & $1.83(.46)$ & $1.93(.42)$ \\
\hline
\end{tabular}




\subsubsection{Self-report questionnaire}

The Kaiser-Meyer-Olkin measure and sphericity measure indicated adequate sampling and sufficient correlations between items: $\mathrm{KMO}=.789, \chi^{2}(435)=1544.542, p=.000$. An initial analysis of eigenvalues and interpretation of the scree plot justified retaining two components for the final analysis. Table 4 shows the factor loadings and correlations after rotation. These loadings create two clusters that can be labeled as systematic approach and source evaluation behavior. Six items were discarded: four with both loadings below .32 and two with equal factor loadings on both components (Tabachnick \& Fidell, 2007). The scales yielded reliability scores of $\alpha=.85$ and $\alpha=.62$ respectively. See Table 3 for an overview of means and standard deviations for both variables.

For the systematic approach data, Mauchly's test revealed that the assumption of sphericity had been violated, $\chi^{2}(2)=21.19, p=.000$. Therefore, the Huynh-Feldt correction was applied to the degrees of freedom. The test showed a significant increase in scores: $F(1.74,99)=13.584, p=.000$, but a small effect: $\eta_{\text {partial }}^{2}=.125$. Subsequent contrast analysis showed that scores increased significantly from pretest to posttest: $F(1,99)=16.776$, $p=.000, \eta_{\text {partial }}^{2}=.150$, but did not change significantly on the retention test. There were no significant differences between conditions: $F(3,99)=.396, p=.756$. For the evaluation behavior data, the Huynh-Feldt adjustment was necessary as well: $\chi^{2}(2)=8.40, p=.015$. Results show a significant within-subjects effect $F(1.93,94)=32.98, p=.000, \eta_{\text {partial }}^{2}=.268$, but no significant between-subjects effect: $F(3,94)=.438, p=.726$. Contrast analysis shows a strong increase in scores from pretest to posttest: $F(1,94)=38.787, p=.000, \eta^{2}$ partial $=.301$, and another small increase on the posttest. The latter just fails to reach significance: $F(1,94)=3.897, p=.051, \eta_{\text {partial }}^{2}=.024$. 
Table 4

Exploratory factor analysis results for the IPS self-report: factor loadings (correlations)

\begin{tabular}{|c|c|c|}
\hline & $\begin{array}{c}\text { Systemati } \\
\text { c } \\
\text { approach }\end{array}$ & $\begin{array}{c}\text { Evaluatio } \\
n \\
\text { behavior }\end{array}$ \\
\hline $\begin{array}{l}\text { I work according to a predetermined plan when searching, } \\
\text { selecting, and processing information }\end{array}$ & $.75(.72)$ & $-.12(.09)$ \\
\hline I make an overview (a list or table) of the needed information & $.72(.68)$ & $-.17(.03)$ \\
\hline I plan where I am going to search for which information & $.67(.61)$ & $-.23(-.05)$ \\
\hline I make a list of steps to follow & $.67(.62)$ & $-.19(-.00)$ \\
\hline I mostly work intuitively and do not use a predetermined plan & $.66(.65)$ & $-.03(.16)$ \\
\hline I make an overview of possible keywords & $.61(.58)$ & $-.12(.05)$ \\
\hline I just search for information without thinking about it too much & $.58(.57)$ & $-.05(.11)$ \\
\hline I make a time schedule for performing the task & $.57(.56)$ & $-.06(.10)$ \\
\hline I systematically keep track of the keywords I have used & $.51(.52)$ & $.04(.18)$ \\
\hline I regularly check whether I am searching correctly & $.46(.49)$ & $.12(.25)$ \\
\hline While searching, I try to keep an overview of the search process & $.45(.47)$ & $.08(.21)$ \\
\hline I deliberately check what I do not know yet in relation to the task & $.43(.50)$ & $.24(.26)$ \\
\hline I present the information in an organized and ordered fashion & $.42(.47)$ & $.16(.28)$ \\
\hline After visiting a site, I check which information is still needed & $.41(.43)$ & $.06(.17)$ \\
\hline At the end, I check again whether I have all the information & $.39(.45)$ & $.24(.35)$ \\
\hline I mostly work on and see how far I get & $.36(.45)$ & $.31(.41)$ \\
\hline I make sure that I organize all relevant information well & $.35(.42)$ & $.26(.36)$ \\
\hline I keep the desired end product in mind & $.33(.40)$ & $.25(.34)$ \\
\hline $\begin{array}{l}\text { By looking at the URL (Uniform Resource Locator) I can see if a } \\
\text { site is reliable }\end{array}$ & $-.23(-.06)$ & $.63(.56)$ \\
\hline $\begin{array}{l}\text { To decide which site to open, I look at the URL (Uniform } \\
\text { Resource Locator) }\end{array}$ & $-.13(.04)$ & $.62(.58)$ \\
\hline I check whether the site is up-to-date before I use the information & $.01(.17)$ & $.55(.56)$ \\
\hline $\begin{array}{l}\text { I check whether information I have found overlaps with } \\
\text { previously found information }\end{array}$ & $-.05(.10)$ & $.52(.51)$ \\
\hline Before I open a site, I check its reliability & $.11(.24)$ & $.49(.52)$ \\
\hline $\begin{array}{l}\text { I check whether information I have found contradicts previously } \\
\text { found information }\end{array}$ & $.09(.22)$ & $.47(.50)$ \\
\hline
\end{tabular}

\subsubsection{Mental effort ratings}

The experienced mental effort during learning tasks shows a significant within-subjects effect: $F(3,88)=8.306, p=.000, \eta_{\text {partial }}^{2}=.090$, indicating that scores change significantly 
over time. However, a significant interaction effect reveals that the effect depends on the type of support the student received: $F(9,88)=2.743, p=.005, \eta^{2}$ partial $=.089$. Separate repeated measures ANOVAs for each condition showed significant effects only in the EM condition: $F(3,18)=.5 .497, p=.002, \eta_{\text {partial }}^{2}=.244$, and in the CS condition: $F(3,23)=7.756$, $p=.000, \eta_{\text {partial }}^{2}=.261$. Subsequent contrast analysis indicated that the mental effort ratings in these groups only changed significantly on the fourth learning task. In the EM condition, scores dropped from $4.72(S D=2.16)$ on task three to $3.17(S D=2.01)$ on task four: $F(1,18)=7.840, p=.012, \eta_{\text {partial }}^{2}=.316$. In the CS condition, scores dropped from 4.74 $(S D=2.34)$ to $2.83(S D=1.64): F(1,23)=12.875, p=.002, \eta_{\text {partial }}^{2}=.369$.

\subsubsection{Time pressure ratings}

Analysis of time pressure ratings revealed no significant changes over time and no differences between conditions. Separate univariate ANOVAs for each learning task showed that the average amount of time pressure on each learning task was the same in each group. 

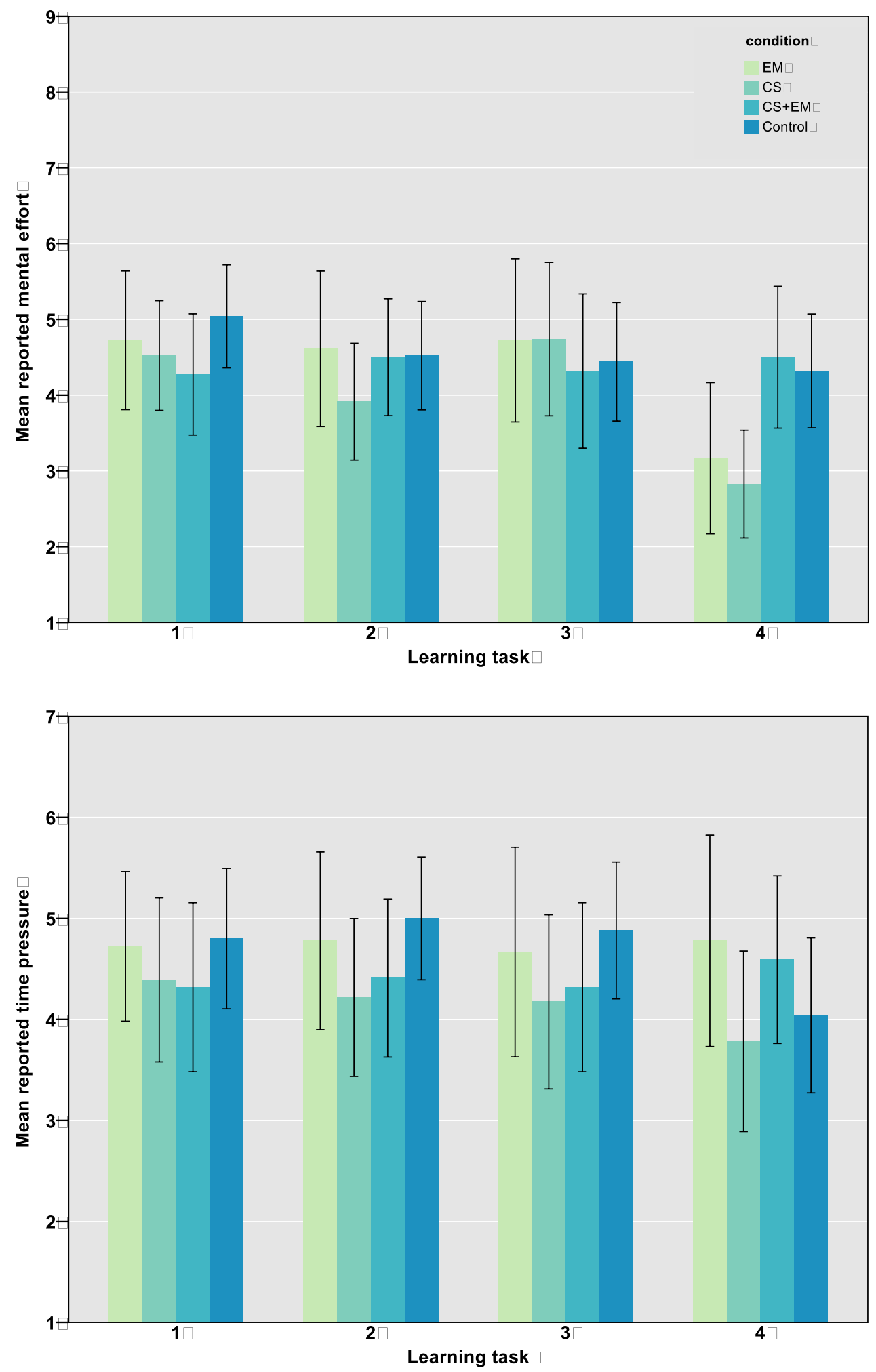

Figure 3. Mental effort ratings and time pressure ratings for all conditions on all learning tasks 


\subsection{Discussion}

The second experiment replicated the first with some improvements. First, it measured additional variables with a self-report questionnaire to achieve a more complete impression of the students' skill level. Second, it set out to reduce the experienced time pressure by administering the pretest before the training session. And finally, it included a retention test to measure IPS skill one week after training. With these improvements, the findings display a similar pattern as in the first experiment. The significant increase in scores from pretest to posttest leads to the conclusion that the intervention was effective for fostering IPS skills. However, the results do not back the claim that the type of support has an effect on the learning outcomes. None of the groups that received support, whether completion strategy, emphasis manipulation, or both, outperformed the control group.

This was also true for scores the self-report questionnaires. For systematic approach, students scored around 1.19 on the pretest, a value closer to 'Sometimes' than to 'Often', indicating that students are aware that they do not work very systematically when solving information problems. This score showed a small increase to an average of 1.32 on the posttest. While statistically significant, the effect of the training is small, and type of support again showed no effect. For evaluation behavior, a similar pattern emerges, but with larger effects. Average scores increase from 1.59 before training to 1.84 after the training, showing a large effect size. From these results it can concluded that the training significantly improved students' scores on self-reported systematic approach and source evaluation behavior, but again, there were no significant differences between the conditions. This corroborates previous research that shows evaluation skills can be trained in classroom settings (Britt \& Aglinskas, 2002; Walraven, Brand-Gruwel, \& Boshuizen, 2010).

In general, scores on the retention test results show a similar picture for all measured variables. While they increase from pretest to posttest, they do not change much one week 
later. All the differences between posttest scores and retention test scores are statistically insignificant and show small effect sizes. However, some conditions show a small increase in scores after a week, while others show a decrease in scores. It would be interesting to see if this difference develops into a significant effect over a longer period of time. From these findings, it can be concluded that the learning effect caused by this intervention is sufficiently robust to last one week.

Compared to Experiment 1, the mean reported mental effort and time pressure is generally lower. This is an expected finding as students in Experiment 2 were given more time to perform the learning tasks. On the fourth learning task - a conventional problem without support or guidance - the CS and the EM conditions reported significantly less mental effort than the CS+EM and control conditions. This might be a hint that these students have become more efficient in their problem solving and require less mental effort to reach the solution. However, without performance data on the learning task, this is impossible to determine (Hoffman \& Schraw, 2010). The subsequent posttest did not show any differences in performance between the conditions.

In short, Experiment 2 yielded no support for the hypothesis that supported students show higher learning outcomes than students who receive no support. Mean scores in all conditions did not differ significantly. While the EM and CS conditions reported less mental effort on a conventional learning task at the end of training, it is difficult to draw any solid conclusions from this finding. 


\section{General discussion}

The experiments reported on here investigated the hypothesis that students who receive task support while acquiring IPS skills, either in the form of completion tasks or emphasis prompts, show better learning outcomes than students who do not receive task support. The findings do not support this claim. Students who receive no task support performed just as well as those who did. While Experiment 1 suffered from some methodological issues, a revised version of the experiment confirms the pattern of results and provides more confidence in this conclusion.

As a general observation, the pretest scores are low in both experiments. In fact, the slightly younger group of students in the first experiment scored higher on the pretest than their counterparts in the second. This difference shows a discrepancy in prior knowledge between both samples. While the exact cause of this is unclear, these differences likely originate from prior experience, practice, or instructions concerning IPS skills, such as a library training. However, the most important conclusion to draw from these findings is that this generation of first-year university students do not show very well-developed IPS skills. The scores, which lie well in the lower half of the range, can only refute claims that students are 'digital natives', a new generation technologically skilled students in need of adapted education. These findings agree with research challenging the existence of the digital native (Bennett, Maton, \& Kervin, 2008; Kirschner \& van Merriënboer, 2013; Smith, 2012) and underline our claim that IPS instruction in schools is a necessity.

The findings do show that a short online intervention can increase IPS skills. While previous interventions have attempted to develop subskills in the process of IPS (e.g. Britt \& Aglinskas, 2002; Colaric, 2003; Walraven, Brand-Gruwel, \& Boshuizen, 2013), this experiment attempted to provide a systematic approach to the whole task of solving an information problem following the 4C/ID whole task approach (Van Merriënboer \& 
Kirschner, 2013). This intervention was successful, as shown by the significant increase in scores between pretest and posttest. After the training, students from both experiments scored slightly over $60 \%$ on average, which leads to two conclusions. First, a 2-hour online training including an instructional video, a modeling example, and four short learning tasks can increase students' IPS skills. As shown by retention test scores, this increase is maintained for at least a week. Second, effect sizes are not very large, and a $60 \%$ average score after training indicates that there is still much room to grow.

As stated, students who received no support showed performance equal to that of supported students. There are two possible explanations for this. First, it might be the case that both forms of support were ineffective. Previous research has shown that completion tasks lead to an expertise reversal effect in situations where learners have high prior knowledge (Kalyuga et al., 2003). However, this effect is less likely to occur in less structured domains (Nievelstein, van Gog, van Dijck, \& Boshuizen, 2013), which, in combination with the low pretest scores, makes it unlikely that an expertise reversal effect occurred. The other method of support, prompting, can be ineffective when prompts are not used as intended, in which case they show reduced effects on learning outcomes and reported mental effort (Bannert \& Reimann, 2011). Although answers to the prompts were generally short (i.e., approximately one sentence), they indicated that the prompts were used as anticipated. These findings lead to the conclusion that the task support methods were implemented correctly.

The second explanation suggests that a maximum learning effect for this setting was achieved. It could be the case that the learning effect in this experiment can be attributed to the viewing of the instructional video in combination with the modeling example and selfexplanation prompts. Modeling examples are very powerful learning tools when employed correctly (Bjerrum, Hilberg, van Gog, Charles, \& Eika, 2013; Hoogerheide, Loyens, \& van 
Gog, 2014). Perhaps, after viewing both videos, the subsequent learning tasks had little additional value. It follows then that the built-in support in those learning tasks has equally little value. A video-based modeling example is intuitively a very suitable method of instruction for teaching these skills, as most of the IPS process happens on-screen. An expert can easily record a screencast while working and reasoning through a problem and offer this as an example to students. The effects of using a modeling example for teaching IPS skills presents an interesting venue for future research.

Several limitations of these experiments should be regarded when interpreting and generalizing these conclusions. The IPS training was offered in a single 2-hour session with learning tasks of the same type and complexity. In educational practice, students are confronted with a great variety of tasks. The current intervention did not include different task types (c.f. Gerjets \& Hellenthal-Schorr, 2008), which makes it less likely that far transfer occurred. To achieve far transfer, students would benefit from more learning tasks: more practice with varying task demands and task complexity, yet without added time pressure. An embedded approach, where instructional designers combine IPS instruction with domainspecific instruction in an extensive curriculum, appears appropriate for this task (Argelagós \& Pifarré, 2012; Wopereis, Brand-Gruwel, \& Vermetten, 2008).

The current intervention focused on learning in an online environment without involvement of a teacher and without feedback on the learning tasks. Considering the multitude of factors that can increase task complexity and cognitive demand, personalized feedback on performance would be beneficial for students, as this allows them to learn from their mistakes. Research has shown a positive effect of feedback on development of metacognitive skills in online learning environments (Van den Boom, Paas, van Merriënboer, \& van Gog, 2004) and therefore presents another interesting direction for future research. For example, interventions could be improved with the addition of a cognitive feedback element 
in which teachers provide students with adapted feedback on their performance (Timmers, Walraven, \& Veldkamp, 2015).

To conclude, this experiment makes clear that first-year university students are not as information literate as many assume, and that their IPS skills need to be trained. The 2-hour online intervention in this experiment shows a promising learning effect. While it was expected that different types of task support would vary in their effect on the learning outcomes, this proved not to be the case. The authors hypothesize that a powerful modeling example is most likely responsible for a large proportion of the learning effect, thereby reducing the value of the learning tasks and their task support. A follow-up study will investigate whether modeling examples are indeed a powerful learning tool for this purpose. 


\section{References}

Argelagós, E., \& Pifarré, M. (2012). Improving information problem solving skills in secondary education through embedded instruction. Computers in Human Behavior, 28, 515-526. doi:10.1016/j.chb.2011.10.024

Atkinson, R., Renkl, A., \& Merrill, M. (2003). Transitioning from studying examples to solving problems: Effects of self-explanation prompts and fading worked-out steps. Journal of Educational Psychology, 95, 774-783. doi:10.1037/0022-0663.95.4.774

Badke, W. (2010). Why information literacy is invisible. Communications in Information Literacy, 4, 129-141. doi:10.1109/ICELMACH.2010.5608206

Bannert, M., \& Reimann, P. (2011). Supporting self-regulated hypermedia learning through prompts. Instructional Science, 40, 193-211. doi:10.1007/s11251-011-9167-4

Bennett, S., Maton, K., \& Kervin, L. (2008). The "digital natives" debate: A critical review of the evidence. British Journal of Educational Technology, 39, 775-786. doi:10.1111/j.1467-8535.2007.00793.X

Bjerrum, A. S., Hilberg, O., van Gog, T., Charles, P., \& Eika, B. (2013). Effects of modelling examples in complex procedural skills training: A randomised study. Medical Education, 47, 888-898. doi:10.1111/medu.12199

Brand-Gruwel, S., Wopereis, I., \& Vermetten, Y. (2005). Information problem solving by experts and novices: Analysis of a complex cognitive skill. Computers in Human Behavior, 21, 487-508. doi:10.1016/j.chb.2004.10.005

Brand-Gruwel, S., Wopereis, I., \& Walraven, A. (2009). A descriptive model of information problem solving while using internet. Computers \& Education, 53, 1207-1217. doi:10.1016/j.compedu.2009.06.004 
Bråten, I., Strømsø, H. I., \& Salmerón, L. (2011). Trust and mistrust when students read multiple information sources about climate change. Learning and Instruction, 21, 180192. doi:10.1016/j.learninstruc.2010.02.002

Britt, M. A., \& Aglinskas, C. (2002). Improving students' ability to identify and use source information. Cognition and Instruction, 20, 485-522. doi:10.1207/S1532690XCI2004_2

Colaric, S. M. (2003). Instruction for Web searching: An empirical study. College Research Libraries, 64, 111-122. doi:10.5860/crl.64.2.111

De Vries, B., van der Meij, H., \& Lazonder, A. W. (2008). Supporting reflective web searching in elementary schools. Computers in Human Behavior, 24, 649-665. doi:10.1016/j.chb.2007.01.021

DeStefano, D., \& LeFevre, J. A. (2007). Cognitive load in hypertext reading: A review. Computers in Human Behavior, 23, 1616-1641. doi:10.1016/j.chb.2005.08.012

Dirkx, K. J. H., Kester, L., \& Kirschner, P. A. (2014). The testing effect for learning principles and procedures from texts. The Journal of Educational Research, 107, 357364. doi:10.1080/00220671.2013.823370

Fabiani, M., Buckley, J., Gratton, G., Coles, M. G. H. H., Donchin, E., \& Logie, R. (1989). The training of complex task performance. Acta Psychologica, 71, 259-299. doi:10.1016/0001-6918(89)90012-7

Ford, N., Miller, D., \& Moss, N. (2005). Web search strategies and human individual differences: Cognitive and demographic factors, internet attitudes, and approaches. Journal of the American Society for Information Science and Technology, 56, 741-756. doi:10.1002/asi.20168

Gerjets, P., \& Hellenthal-Schorr, T. (2008). Competent information search in the World Wide Web: Development and evaluation of a web training for pupils. Computers in Human Behavior, 24, 693-715. doi:10.1016/j.chb.2007.01.029 
Gerjets, P., Kammerer, Y., \& Werner, B. (2011). Measuring spontaneous and instructed evaluation processes during Web search: Integrating concurrent thinking-aloud protocols and eye-tracking data. Learning and Instruction, 21, 220-231. doi:10.1016/j.learninstruc.2010.02.005

Gopher, D. (2006). Emphasis change as a training protocol for high-demand tasks. In A. F. Kramer, D. A. Wiegmann, \& A. Kirlik (Eds.), Attention: From Theory to Practice (Vol. 101, pp. 209-224). doi:10.1093/acprof:oso/9780195305722.003.0015

Gopher, D., Weil, M., \& Siegel, D. (1989). Practice under changing priorities: An approach to the training of complex skills. Acta Psychologica, 71, 147-177. doi:10.1016/00016918(89)90007-3

Hart, S. G., \& Staveland, L. E. (1998). Development of NASA-TLX (Task Load Index): Results of empirical and theoretical research. In P. Hancock \& N. Meshkati (Eds.), Human Mental Workload (pp. 139-183). Amsterdam: North Holland.

Hoffman, B., \& Schraw, G. (2010). Conceptions of efficiency: Applications in learning and problem solving. Educational Psychologist, 45, 1-14. doi:10.1080/00461520903213618

Hölscher, C., \& Strube, G. (2000). Web search behavior of Internet experts and newbies. Computer Networks, 33, 337-346. doi:10.1016/S1389-1286(00)00031-1

Hoogerheide, V., Loyens, S. M. M., \& van Gog, T. (2014). Effects of creating video-based modeling examples on learning and transfer. Learning and Instruction, 33, 108-119. doi:10.1016/j.learninstruc.2014.04.005

Kalyuga, S., Ayres, P., Chandler, P., \& Sweller, J. (2003). The expertise reversal effect. Educational Psychologist, 38, 23-31. doi:10.1207/S15326985EP3801_4

Kalyuga, S., \& Sweller, J. (2004). Measuring knowledge to optimize cognitive load factors during instruction. Journal of Educational Psychology, 96, 558-568. doi:10.1037/00220663.96.3.558 
Kammerer, Y., Bråten, I., Gerjets, P., \& Strømsø, H. I. (2012). The role of Internet-specific epistemic beliefs in laypersons' source evaluations and decisions during Web search on a medical issue. Computers in Human Behavior, 29, 1193-1203.

doi:10.1016/j.chb.2012.10.012

Kennedy, G. E., Judd, T. S., Churchward, A., Gray, K., \& Krause, K. L. (2008). First year students' experiences with technology: Are they really digital natives? Australasian Journal of Educational Technology, 24, 108-122. doi:10.1.1.85.9526

Kirschner, P. A., Sweller, J., \& Clark, R. E. (2006). Why minimal guidance during instruction does not work: An analysis of the failure of constructivist, discovery, problem-based, experiential, and inquiry-based teaching. Educational Psychologist, 41, 75-86. doi:10.1207/s15326985ep4102_1

Kirschner, P. A., \& van Merriënboer, J. J. G. (2013). Do learners really know best? Urban legends in education. Educational Psychologist, 48, 169-183. doi:10.1080/00461520.2013.804395

Lazonder, A. W. (2000). Exploring novice users' training needs in searching information on the WWW. Journal of Computer Assisted Learning, 16(4), 326-335. doi:10.1046/j.1365-2729.2000.00145.x

Lazonder, A. W., Biemans, H. J. A., \& Wopereis, I. G. J. H. (2000). Differences between novice and experienced users in searching information on the World Wide Web. Journal of the American Society for Information Science and Technology, 51, 576-581. doi:10.1002/(sici)1097-4571(2000)51:6<576::aid-asi9>3.0.co;2-7

MaKinster, J. G., Beghetto, R. A., \& Plucker, J. A. (2002). Why can't I find Newton's third law? Case studies of students' use of the web as a science resource. Journal of Science Education and Technology, 11, 155-172. doi:10.1023/a:1014617530297 
Nievelstein, F., van Gog, T., van Dijck, G., \& Boshuizen, H. P. A. (2013). The worked example and expertise reversal effect in less structured tasks: Learning to reason about legal cases. Contemporary Educational Psychology, 38, 118-125. doi:10.1016/j.cedpsych.2012.12.004

Paas, F. G. W. C. (1992). Training strategies for attaining transfer of problem-solving skill in statistics: A cognitive-load approach. Journal of Educational Psychology, 84, 429-434. doi:10.1037/0022-0663.84.4.429

Paas, F. G. W. C., \& van Merriënboer, J. J. G. (1994). Instructional control of cognitive load in the training of complex cognitive tasks. Educational Psychology Review, 6, 351-371. doi:10.1007/BF02213420

Paas, F., Tuovinen, J. E., Tabbers, H., \& Van Gerven, P. W. M. (2003). Cognitive load measurement as a means to advance cognitive load theory. Educational Psychologist, 38,63-71. doi:10.1207/S15326985EP3801_8

Renkl, A. (1997). Learning from worked-out examples: A study on individual differences. Cognitive Science, 21, 1-29. doi:10.1207/s15516709cog2101_1

Renkl, A., \& Atkinson, R. (2003). Structuring the transition from example study to problem solving in cognitive skill acquisition: a cognitive load perspective. Educational Psychologist, 38, 15-22. doi:10.1207/s15326985ep3801_3

Renkl, A., Atkinson, R., \& Große, C. (2004). How fading worked solution steps works - A cognitive load perspective. Instructional Science, 32, 59-82. doi:10.1023/B:TRUC.0000021815.74806.f6

Renkl, A., \& Atkinson, R. K. (2002). Learning from examples: Fostering self-explanations in computer-based learning environments. Interactive Learning Environments, 10, 105119. doi:10.1076/ilee.10.2.105.7441 
Rouet, J.-F. (2009). Managing cognitive load during document-based learning. Learning and Instruction, 19, 445-450. doi:10.1016/j.learninstruc.2009.02.007

Rouet, J.-F., Ros, C., Goumi, A., Macedo-Rouet, M., \& Dinet, J. (2011). The influence of surface and deep cues on primary and secondary school students' assessment of relevance in Web menus. Learning and Instruction, 21, 205-219. doi:10.1016/j.learninstruc.2010.02.007

Saito, H., \& Miwa, K. (2007). Construction of a learning environment supporting learners' reflection: A case of information seeking on the Web. Computers \& Education, 49, 214229. doi:10.1016/j.compedu.2005.07.001

Smith, E. E. (2012). The digital native debate in higher education: A comparative analysis of recent literature. Canadian Journal of Learning and Technology, 38(3), 1-18.

Stadtler, M., \& Bromme, R. (2008). Effects of the metacognitive computer-tool met.a.ware on the web search of laypersons. Computers in Human Behavior, 24, 716-737. doi:10.1016/j.chb.2007.01.023

Stark, R., \& Krause, U. M. (2009). Effects of reflection prompts on learning outcomes and learning behaviour in statistics education. Learning Environments Research, 12, 209223. doi:10.1007/s10984-009-9063-X

Tabachnick, B. G., \& Fidell, L. S. (2007). Principal components and factor analysis. In Using Multivariate Statistics (5th ed., pp. 607-675). Boston: Pearson Education.

Timmers, C. F., Walraven, A., \& Veldkamp, B. P. (2015). The effect of regulation feedback in a computer-based formative assessment on information problem solving. Computers $\&$ Education, 87, 1-9. doi:10.1016/j.compedu.2015.03.012

Van den Boom, G., Paas, F., van Merriënboer, J. J. G., \& van Gog, T. (2004). Reflection prompts and tutor feedback in a web-based learning environment: Effects on students' 
self-regulated learning competence. Computers in Human Behavior, 20, 551-567. doi:10.1016/j.chb.2003.10.001

Van Gog, T., Paas, F., \& van Merriënboer, J. J. G. (2004). Process-oriented worked examples: Improving transfer performance through enhanced understanding. Instructional Science, 32, 83-98. doi:10.1023/B:TRUC.0000021810.70784.b0

Van Meeuwen, L. W. (2008). Tracking the Brain. Master's thesis. Technische Universiteit Eindhoven, Eindhoven. Retrieved from http://repository.tue.nl/634895

Van Merriënboer, J. J. G. (1990). Strategies for programming instruction in high school: Program completion vs. program generation. Journal of Educational Computing Research, 6, 265-285. doi:10.2190/4NK5-17L7-TWQV-1EHL

Van Merriënboer, J. J. G., \& Ayres, P. (2005). Research on cognitive load theory and its design implications for e-learning. Educational Technology Research and Development, 53(3), 5-13. doi:10.1007/BF02504793

Van Merriënboer, J. J. G., \& De Croock, M. B. M. (1995). Strategies for computer-based programming instruction: Program completion vs. program generation. Journal of Educational Computing Research, 8, 365-394. doi:10.2190/MJDX-9PP4-KFMT-09PM

Van Merriënboer, J. J. G., \& Kirschner, P. A. (2013). Ten steps to complex learning: A systematic approach to four-component instructional design (2nd ed.). New York: Routledge.

Van Strien, J. L. H., Brand-Gruwel, S., \& Boshuizen, H. P. A. (2014). Dealing with conflicting information from multiple nonlinear texts: Effects of prior attitudes. Computers in Human Behavior, 32, 101-111. doi:10.1016/j.chb.2013.11.021

Walraven, A., Brand-Gruwel, S., \& Boshuizen, H. P. A. (2008). Information-problem solving: A review of problems students encounter and instructional solutions. Computers in Human Behavior, 24, 623-648. doi:10.1016/j.chb.2007.01.030 
Walraven, A., Brand-Gruwel, S., \& Boshuizen, H. P. A. (2010). Fostering transfer of websearchers' evaluation skills: A field test of two transfer theories. Computers in Human Behavior, 26, 716-728. doi:10.1016/j.chb.2010.01.008

Walraven, A., Brand-Gruwel, S., \& Boshuizen, H. P. A. (2013). Fostering students' evaluation behaviour while searching the internet. Instructional Science, 41, 125-146. doi:10.1007/s11251-012-9221-x

Wirth, W., Sommer, K., von Pape, T., \& Karnowski, V. (2015). Success in online searches: Differences between evaluation and finding tasks. Journal of the Association for Information Science and Technology, Advance online publication. doi:10.1002/asi.23389

Wopereis, I. G. J. H., Brand-Gruwel, S., \& Vermetten, Y. (2008). The effect of embedded instruction on solving information problems. Computers in Human Behavior, 24, 738752. doi:10.1016/j.chb.2007.01.024

Yechiam, E., Erev, I., \& Gopher, D. (2001). On the potential value and limitations of emphasis change and other exploration-enhancing training methods. Journal of Experimental Psychology: Applied, 7, 277-285. doi:10.1037/1076-898x.7.4.277

Yechiam, E., Erev, I., Yehene, V., \& Gopher, D. (2003). Melioration and the transition from touch-typing training to everyday use. Human Factors, 45, 671-684. doi:10.1518/hfes.45.4.671.27085 